\title{
O CONCEITO DE VIVÊNCIA (ERLEBNIS) EM NIETZSCHE: GÊNESE, SIGNIFICADO E RECEPÇÃO
}

\author{
Jorge Luiz Viesenteiner* \\ jvies@uol.com.br
}

RESUMO $O$ objetivo deste artigo é analisar o conceito de vivência (Erlebnis) na filosofia de Nietzsche, desde o seu primeiro emprego em língua alemã, seu significado e a recepção que Nietzsche faz da palavra no interior da sua filosofia. O conceito de Erlebnis, particularmente caro à filosofia de Nietzsche, mas também à fenomenologia, possui originariamente uma tríplice significação: a) a imediatez (Unmittelbarkeit) entre homem e mundo; b) a significabilidade (Bedeutsamkeit) para o caráter global da existência; e c) a incomensurabilidade (Inkommensurabilität) do conteúdo da própria vivência, conferindo a ela também uma dimensão estética. A tríplice significação de Erlebnis implica na sua estreita associação a pathos.

Palavras-chave Erlebnis, imediatez, significabilidade, incomensurabilidade, pathos.

ABSTRACT This paper aims to analyze the concept of experience (Erlebnis) in the Nietzsche's philosophy, since its first use into the German language, its meaning and reception of Nietzsche inside his philosophy. The concept of Erlebnis, especially dear to the philosophy of Nietzsche, but also to phenomenology, originally has a triple meaning: a) the immediacy (Unmittelbarkeit) between man and world, b) meaningfulness 
(Bedeutsamkeit) to the global nature of existence and c) incommensurability (Inkommensurabilität) of the experience's content itself, giving it also an aesthetic dimension. The threefold meaning of Erlebnis implies its close association with pathos.

Keywords Erlebnis, immediacy, meaningfulness, incommensurability, pathos.

A ocorrência da palavra vivência, Erlebnis, aparece no vocabulário alemão pela primeira vez a partir da primeira metade do século XIX, e ganha estatuto filosófico só em meados do mesmo século. ${ }^{1}$ Substantivado a partir do verbo erleben, Erlebnis significa "estar ainda presente na vida quando algo acontece", e seu uso linguístico geral remonta à literatura de caráter biográfico que surge inicialmente com o texto de Dilthey sobre a vida de Schleiermacher. ${ }^{3}$

O uso geral da palavra Erlebnis originalmente possui três aspectos principais: 1) vivência tem o caráter de ligação imediata com a vida (Unmittelbarkeit), de modo que não se vivencia algo através do legado de uma tradição e nem através de algo de que "se ouviu falar", mas sim Erlebnis “é sempre vivenciada por um Si” efetivamente, "cujo conteúdo não se deve a nenhuma construção" , por isso o caráter de "imediatez" da vivência com a vida. 2) Além disso, o que é vivenciado deve ter uma intensidade de tal modo significativa, cujo resultado confere uma importância que transforma por completo o contexto geral da existência: "Ao mesmo tempo, a forma 'o que se vivenciou" " classifica o que, no curso da vivência imediata, ganhou duração

1 Cf. Cramer, K. "Erleben, Erlebnis". In: Ritter, Joachim (Hrsg.) Historisches Wörterbuch der Philosophie. Band 2: D-F. Basel/Stuttgart: Schwabe \& Co. Verlag, 1972. p. 702. A prova mais antiga do uso da palavra parece ser uma carta de Hegel de 1827 (Briefe, Ed. Hoffmeister, III 179), na qual ele escreve a palavra Erlebnis - como gênero feminino ainda -, referindo-se a um acontecimento pessoal: "toda minha vivência" [meine ganze Erlebnis]. A filosofia do século XVIII ainda não estabelece uma diferença entre " 'vida' e 'experiência' ", "e para Kant e os kantianos, Schelling e Hegel, a palavra não indica nenhuma função conceitual" (Idem, p. 703).

2 Cramer, K. op.cit., p. 703.

3 Gadamer, Hans-G. Wahrheit und Methode: Grundzüge einer philosophischen Hermeneutik. Tübingen: J.C.B. Mohr, 1990. p. 66: "Sua introdução no uso linguístico geral está relacionado, ao que parece, com sua utilização na literatura biográfica”. O livro de Dilthey sobre a biografia de Schleiemacher surge em 1870 já utilizando o vocábulo Erlebnis. Depois dele são publicadas ainda a biografia de Winckelmann por Justi (1872), bem como a biografia de Goethe por Hermann Grimm em 1877.

4 Cramer, K., op.cit., p. 703. Cf. também Gadamer, Hans-G., op.cit., p. 66. 
e significabilidade para o todo de um contexto de vida, enquanto seu produto mediato". ${ }^{5}$ Que alguém ainda tenha que vivenciar algo significa não apenas que esse alguém estará ligado à vida de forma imediata, mas também que a vivência deve ter uma tal significabilidade, a ponto de conferir importância decisiva ao caráter global da vida daquele que vivencia. ${ }^{6}$ Imediatez e significabilidade constituem, pois, o substrato que o emprego geral da palavra Erlebnis ganha a partir da primeira metade do século XIX. A ideia filosófica posterior que remonta à Erlebnis como condição última para toda teoria, deriva, como se vê, das duas características correntes na literatura alemã. ${ }^{7}$

O terceiro significado do uso do vocábulo Erlebnis se refere ainda precisamente ao conteúdo daquilo que se vivencia. Trata-se da impossibilidade de determinar racionalmente o conteúdo da vivência ${ }^{8}$, de modo que a noção de Erlebnis deve sempre ser pensada do ponto de vista estético. Esse terceiro aspecto é compreendido à luz do contexto ao qual a palavra Erlebnis surge na literatura alemã, vale dizer, como oposição intransigente à frieza da especulação metafísica e ao racionalismo da Aufklärung: "A cunhagem da palavra 'Erlebnis' evoca abertamente a crítica ao racionalismo da Aufklärung [...]. Em oposição à abstração do entendimento e igualmente contra a particularidade da sensação ou representação, o conceito implica uma ligação com a Totalidade, com a Infinitude".

$\mathrm{O}$ anseio por uma relação imediata entre o homem e o mundo, cuja linguagem fosse capaz de exprimir a abundância de sentimento dessa Erlebnis não permite o uso de meios racionais que expliquem tal conteúdo. As reflexões sobre a "particularidade da poesia e da estética na época do Sturm und Drang e do romantismo alemães"10 exerceram, como se vê, papel

5 Cramer, K., op.cit., p. 703.

6 Cf. Gadamer, H-G. op.cit., p. 67: "A essência da biografia, especialmente a de artistas e poetas do século XIX, deve compreender a obra a partir da vida. Sua produtividade consiste em mediar ambas as direções de significados que diferenciamos, ou seja, reconhecer na vivência um contexto produtivo. Algo se torna Erlebnis na medida em que não foi apenas vivenciado, mas sim que essa vivência tenha tido uma especial impressão a ponto de emprestar um significado permanente a ela".

7 Apesar de não elaborar sistematicamente uma teoria da Erlebnis, Fichte já evocava a vivência como um dado último para toda teoria. Cramer, K., op.cit., p. 703 informa que, segundo Fichte, "a vida e a vivência originalmente dada são por isso o dado último para toda teoria; a forma do dado real da vida e da vivência, porém, não limitam a teoria, mas abrem precisamente a possibilidade e a necessidade de sua construção conceitual, como uma 'série superior da vida e da realidade' ".

8 Cf. Visser, Gerard. Erlebnisdruck: Philosophie und Kunst im Bereich eines Übergangs und Untergangs. Würzburg: Königshausen \& Neumann, 2005. p. 62: "Esse é o motivo para diferenciar um terceiro tema: a impossibilidade de esgotar o conteúdo da vivência através de meios racionais". Gerard Visser é o autor que escreve o verbete "Erlebnis" no doravante $2^{\circ}$ volume do Nietzsches Wörterbuch, In: Paul van Tongeren (Hrsg). Nietzsche Wörterbuch. Bd.1. Berlin: Walter de Gruyter, 2004.

9 Cf. Gadamer, H-G. op.cit., p. 68s.

10 Cf. Visser, G. op.cit., p. 62. 
decisivo na incomensurabilidade do conceito Erlebnis. Desde o século XVIII os poetas já buscavam uma palavra que pudesse expressar a totalidade da vida e seu cortejo de sensações. ${ }^{11}$ Trata-se de encontrar uma linguagem que, além de ultrapassar os limites da racionalidade, seria também responsável por trazer à luz a linguagem dessa Totalidade através de um duplo papel: a) expressar imediatamente a relação homem-mundo, cujo substrato remonta exclusivamente às vivências atravessadas pelo autor, sob pena de esvaziar o conteúdo dessa linguagem ${ }^{12}$, bem como b) indicar o caráter estritamente autobiográfico do autor, na medida em que a expressão das suas vivências através de tal linguagem ganharia o aspecto "de uma grande confissão". ${ }^{13}$

A concepção de que Erlebnis não tem seu conteúdo determinado racionalmente confere ao conceito uma dimensão estética, além de significar o substrato a partir do qual a obra de arte é criada, sobretudo pela sua transmissão via romantismo alemão. ${ }^{14} \mathrm{~A}$ vivência de algo não pode ter seu conteúdo construído racionalmente, mas antes deve ser unicamente experimentado, ou melhor, "sentido na pele", como evoca a expressão no português. A dimensão estética da Erlebnis está em plena sintonia com as duas características anteriores de 'imediatez' e 'significabilidade'. Erlebnis, 'sofrer na pele', alude à presença imediata de alguém que vivencia algo efetivamente, bem como se refere ao caráter estritamente individual de toda vivência, representando, por isso, a significabilidade para aquele que vivencia. Toda vivência é sempre "minha" vivência exclusivamente individual, e isso significa "não apenas que eu sinto, mas também que eu incondicionalmente sinto". ${ }^{15}$ Expressar algo através das Erlebnisse pressupõe revelar algo daquilo que alguém efetivamente sentiu e, neste aspecto, a dimensão estética da Erlebnis "não é apenas uma forma de Erlebnis ao lado de outras, mas ela representa a forma

11 Não apenas os poetas, mas obviamente a filosofia já buscava outros pressupostos que estivessem para além da fria especulação abstrata, típica da tradição filosófica alemã. Segundo Cramer, K., op.cit., p. 704, Schlegel "desenvolve uma 'filosofia da vida' como ciência da experiência interior que, em oposição à predominância unilateral da faculdade dialética da abstração, enfatiza como exclusivo objeto de pensamento filosófico 'a espiritual vida interior em toda sua plenitude, e não apenas essa ou unicamente aquela força'".

12 Cf. Dilthey, W. Das Erlebnis und die Dichtung, p. 177: "Poesia é a representação e expressão da vida. Ela expressa a vivência e representa a realidade externa da vida". In: Gadamer, Hans-G., op.cit., p. 68. Dilthey se refere ainda ao "conceito de vivência como um conceito puramente gnosiológico": "O conceito de vivência forma as condições gnosiológicas para todo conhecimento do objetivo”. In: Idem, p. 71. Cf. ainda Goethe, Jubiläumsausgabe 38: "Perguntem apenas por uma poesia que contenha algo vivenciado". In: Idem, p. 68.

13 Cf. Goethe, Dichtung und Wahrheit. Zweiter Teil. In: Gadamer, Hans-G., op.cit., p. 67.

14 Cf. Gadamer, Hans-G., op.cit., p. 76: "Na medida em que a vivência estética determina exemplarmente o conteúdo do conceito 'Erlebnis', fica claro que o conceito de vivência se torna determinante para a fundamentação da perspectiva da arte".

15 Visser, G., op.cit., p. 25. 
essencial de toda Erlebnis em geral". ${ }^{16} \mathrm{O}$ conteúdo daquilo que é sentido de modo inteiramente imediato-individual e significativo em uma vivência, não exige uma determinação racional ${ }^{17}$, ao contrário, pois "como sensação, Erlebnis se refere ao âmbito global do sentimento". ${ }^{18}$

A tripla significação da pré-história do conceito de Erlebnis - a relação imediata entre homem-mundo, a significabilidade do vivido e o substrato não racional de seu conteúdo, ou seja, sua dimensão estética - traria resposta ao anseio poético por uma linguagem que referisse imediatamente os sentimentos do homem, para além da fria abstração e da mera compreensibilidade entre homem e homem através de conceitos universais. Só uma linguagem que se baseia nas vivências e não na consciência estaria em condições de expressar a grandeza humana. ${ }^{19}$

O significado originário de Erlebnis implica em um estreito vínculo com a noção de pathos, ou seja, como contraconceito da razão, bem como uma espécie de "conquista" 20 de um excesso perdulário de vida que não é oriundo

16 Gadamer, Hans-G., op.cit., p. 75.

17 A diferença entre Erlebnis e Erfahrung (experiência) pode ser observada com base na primeira elaboração do verbete Erlebnis em um dicionário da língua alemã - "Encyklopädische Lexikon in bezug auf die neuste Literatur und Geschichte der Philosophie" -, organizado por Wilhelm Traugott Krug em 1838. O verbete reza: "Erlebnis significa tudo o que propriamente se vivenciou (sentiu, presenciou, pensou, quis, fez ou permitiu). Tais vivências, pois, são as condições da própria experiência, se através daí se entende extrair certos resultados" (Cramer, K., op.cit., p. 705). Erlebnis consiste nas condições para toda Erfahrung, na medida em que esta última é constituída por uma mediação especificamente lógica. Enquanto Erlebnis tem seu estatuto determinado pelo caráter imediato naquilo que ocorre, carregando pois seu cortejo de sentimentos, Erfahrung implica em constituição lógica através desse cortejo de Erlebnisse: "Erlebnisse não são as estruturas que constituem a própria Erfahrung como tal, mas apenas as condições. Erfahrung só é constituída através das mediações especificamente lógicas, e que na verdade se relacionam sem exceção com as Erlebnisse, mas ela não tem o caráter da imediatez que tem a Erlebnis. [...] Erlebnisse não são condições subjetivas da Erfahrung, mas representam verdadeiramente a realidade daquilo que se chama Erfahrung. O autor do verbete Erlebnis, no doravante $2^{\circ}$ volume do Nietzsches Wörterbuch, também faz uma diferença entre Erlebnis e Erfahrung. Com base em expressões alemãs - que a meu ver encontram sim correspondências no português -, Erfahrung tem a característica de uma doutrina cujo significado é "prático-moral", ou seja, só depois que se tem a Erfahrung mesma é possível extrair uma avaliação do que se experimentou: “'Agora você experimentou por contra própria!'. Essa Erfahrung tem um significado prático-moral, ela é uma doutrina”. (Visser, G., op.cit., p. 25). Erlebnis, ao contrário, tem um "significado estético-individual". Quando se trata de vivência, a expressão alemã ocorre quando se pergunta: "Como te agradou essa vivência?", e não "agora você mesmo vivenciou". Em suma, Erlebnis tem significado estético-individual, enquanto Erfahrung prático-moral.

18 Visser, G., op.cit., p. 25.

19 Dilthey elabora sistematicamente a partir de 1880 o conceito de Erlebnis. Todo conteúdo da consciência é pensado por ele também como vivência: "Objetos e ideias tão bem quanto sentimentos são primeiramente vivência em minha consciência”. Dilthey, W. Gesammelte Schriften. Band XIX, p. 52. In: Visser, G. Op.cit., p. 63.

20 Cf. Stegmaier, W. „Philosophischer Idealismus“ und die „Musik des Lebens: zu Nietzsches Umgang mit Paradoxien. In: Nietzsche-Studien 33 (2004) p. 90-128, especialmente ali onde define o significa de Errungenschaft (conquista): "Uma conquista filosófica é, pois, a 'vitória' sobre uma convicção ou a 'autosuperação' de uma convicção que até então dominou o pensamento e, no tocante ao pensamento que foi dominado de modo mais forte por convicções morais, uma vitória sobre a consciência moral". Nesse sentido, Cf. ainda NT 18; Co. Ext II, 9; KSA 8, 9[1]; KSA 11, 26[239] e EH, Prefácio 3. 
da sistematização teórica sobre uma certa forma de vida, mas se origina do solo mesmo da travessia existencial de uma vivência. Pathos e Erlebnis não são oposições, mas uma vivência é propriamente pathos, o padecimento da travessia através de uma vivência.

Etimologicamente, a tríplice significação de Erlebnis remonta sempre à sua característica de contraconceito da razão. Ora, vivenciar se furta a qualquer mediação lógica ou instrumentalização racional. Negativamente definida, pois, vivência é um contraconceito da razão; e positivamente ela é "pathos" que, "originalmente", "caracteriza toda forma de padecimento em oposição à ação". ${ }^{21}$ A ação já pressupõe uma mediação lógica, seja de reflexão ou intencionalidade, enquanto pathos, ao contrário, além da significação usual de paixão, afeto, dor, sofrimento, etc., está em imediata ligação com a vida, profundamente significativo àquele que padece e se furta à instrumentalização da razão, ou seja, sentimos ou temos que suportar algo em meio às dores. Por isso o termo alemão Erleiden, pois mais que sentir algo, trata-se de "sofrer de algo, sentir dolorosamente algo, e também aguentar, ter que suportar algo (espiritual ou corporalmente)". ${ }^{22}$ Além disso, acrescente-se que "pathos não significa apenas 'paixão', 'afeto' e 'desejo', mas no grego ele está tanto para 'Erlebnis' como também para 'destino' ". ${ }^{23} \mathrm{O}$ significado etimológico da palavra pathos está em plena sintonia com Erlebnis, no rigoroso sentido de ser um conceito que não é, de antemão, sistematizado pela razão. Ao contrário, pois na medida em que Nietzsche se refere a pathos como um "afeto da distância"24, um "sentimento de distância" 25 ou ainda como um "sentimento fundamental e global duradouro, dominante" 26 , então pathos está em uma seara oposta a do conceito, visto que um 'afeto' ou 'sentimento' está tradicionalmente em oposição ao que é conceitual. Daí o porquê de Erlebnis e pathos estarem estreitamente vinculados: nunca estamos conceitualmente conscientes daquilo que nos acontece, quando estamos imediatamente na vida, ou seja, nunca somos conscientes do pathos da vivência quando ela ocorre, na medida em que se trata de um sentimento de simples padecimento. ${ }^{27}$

21 Meyer-Kalkus, R. Pathos. In: Ritter, Joachim (Hrsg.) Historisches Wörterbuch der Philosophie. Band 7: P-Q. Basel/Stuttgart: Schwabe \& Co. Verlag, 1989. p. 193.

22 Verbete "Erleiden". In: Schadewaldt, Wolfgang. Goethe-Wörterbuch.

23 Cf. Gerhardt, V., Pathos und Distanz, Stuttgart: Reclam, 1988. p. 8.

24 KSA 10, 7[106] p. 278.

$25 \mathrm{EH}, \mathrm{O}$ Caso Wagner 4.

26 GM I, 2. Tradução modificada.

27 Cf. GC 317: "Raramente nos tornamos conscientes do verdadeiro pathos de cada período da vida enquanto nele estamos...”. 
Pathos está ainda em oposição à intencionalidade que sistematiza conceitualmente a existência ou a experiência e, portanto, a Erlebnis mesma foge à instrumentalização da razão. Assim, não temos um acesso conceitual à vida através das vivências, isto é, como contraconceito da razão, a vivência é uma noção que não deve ser trazida à sistematização conceitual. Tão logo conceitualizamos uma Erlebnis, ela deixa de ser uma vivência pathetica, deixando também de ser original e radicalmente individual: como pathos, a Erlebnis é um conceito que não pode ser sistematicamente conceitualizado: "Para Nietzsche, 'Pathos da distância' parece ser, pois, um contraconceito do conceito, a vontade de não trazer a conceitos e não tornar sistematizado em conceitos". ${ }^{28}$ Enfim, Erlebnis é o instante imediato, significativo e estético de uma vida e, portanto, simplesmente pathos.

Essa breve consideração acerca da "pré-história romântica e panteísta" da palavra Erlebnis na literatura alemã nos dá a exata dimensão da recepção do conceito feita por Nietzsche. A semelhança cabal da palavra na literatura alemã, bem como seu emprego nos textos de Nietzsche, salta aos olhos nas obras de juventude, especialmente no texto da "Extemporânea", Richard Wagner in Bayreuth. É importante que se diga, porém, que Nietzsche nunca sistematizou o conceito de Erlebnis, apesar de a palavra ocorrer sob as mais variadas significações em diferentes textos e épocas. Em todo caso, a palavra chegou a Nietzsche acompanhada da carga semântica que recebeu a partir da primeira metade do século XIX, e se desdobrou em seus textos até meados da década de setenta.

De um modo geral, Wagner teria conseguido reconhecer "a loucura dos conceitos universais" 29 , a fim de opor à linguagem das convenções a linguagem da música, a única em condições de expressar o que há de mais próprio e interno em cada vivência: "em toda parte a linguagem adoece e a pressão dessa monstruosa doença oprime todo o desenvolvimento humano". ${ }^{30} \mathrm{Na}$ medida em que a linguagem sofria com um mero acordo de palavras sem um "acordo do sentimento", Wagner teria adivinhado "a linguagem reencontrada do correto sentimento" 31 , que por sua vez, seria tanto "inimiga das convenções" como também um "retorno à natureza" e sua purificação. ${ }^{32}$

28 Cf. Stegmaier, W. Nietzsches Genealogie der Moral, Darmstadt: Wissenschaftliche Buchgesellschaft, 1994. p. 101. Cf. também Stegmaier, W. Philosophie der Orientierung. Berlin/New York: Walter de Gruyter, 2008. p. 600.

29 Co. Ext. IV, Richard Wagner in Bayreuth, 5. In: KSA 1, p. 455.

30 Idem.

31 Idem. In: KSA 1, p. 458.

32 Idem. In: KSA 1, p. 455. 
A correta união entre "música e vida ou música e drama" expressa imediatamente o anseio por uma linguagem procurada originalmente pelos poetas entre homem e mundo. Wagner foi capaz de tornar compreensível através da música o que há de mais próprio e interior nas suas vivências: "seja a arte em geral apenas a capacidade de comunicar a outro algo que se vivenciou, contradiz toda obra de arte em si se ela não consegue se fazer compreensível: nisso deve consistir toda a grandeza de Wagner, do artista, precisamente na comunicabilidade daimonística de sua natureza, que fala de si da mesma maneira em todas as línguas e deixa reconhecer com a mais elevada clareza sua Erlebnis interior e mais própria". ${ }^{33}$

Analisando-se a pré-história da palavra Erlebnis com essas passagens sobre Wagner se compreende a dimensão da recepção do conceito por Nietzsche. Até o início de julho de 1876, data da publicação da Extemporânea sobre Wagner, Nietzsche emprega o termo no rigoroso sentido de sua préhistória, ou seja, o anseio por uma linguagem imediata capaz de exprimir a totalidade das sensações e, sobretudo, do que é vivenciado, uma vez que Erlebnis passa a ser o substrato que se opõe à fria linguagem da racionalidade ou doentia das convenções. Num fragmento preparatório ao texto Richard Wagner in Bayreuth do início de 1875/primavera de 1876, Nietzsche se refere novamente à ideia da obra de arte como comunicação imediata do vivenciado, remontando-se obviamente à música de Wagner: "pois a arte é igualmente a força de comunicar o que realmente se vivenciou, e nada além!". ${ }^{44}$ Em suma, a extemporânea sobre Wagner é partidária da música do compositor que teria sido capaz de fazer reviver o mundo oculto de nossos sentimentos e anseios. ${ }^{35}$

No verão de 1878, porém, o próprio Nietzsche anuncia sua mais recente vivência: "meu erro foi ter ido a Bayreuth com um ideal: tive então que vivenciar a mais amarga decepção. A abundância de feiúra, deformações, saturações me repeliu violentamente". ${ }^{36} \mathrm{O}$ domínio da linguagem adoecida das convenções se espalha não apenas pela ciência, política, nos motes de liberdade, democracia ou trabalho, mas inclusive na arte e, definitivamente, na arte de Wagner. ${ }^{37}$ Bayreuth marca um ponto de virada na filosofia de

33 Idem, 9. KSA 1, p. 484s. O grifo é nosso.

$34 \mathrm{KSA} 8,11[15]$. Ainda num fragmento de 1880/primavera de 1881, KSA 9, 6[244], portanto já depois do rompimento com Wagner, Nietzsche se refere à "probidade na arte" que revelaria a capacidade do artista em "não receber mais nenhum efeito sobre si, mas sim apenas imitar sua vivência (o efeito efetivo)".

35 Cf. Visser, G., op.cit., p. 31: "Se a linguagem está doente tal como Nietzsche afirma com Wagner, a cura pode ser encontrada na música de Wagner [...]. Com Bayreuth teriam sido criadas as condições para a criação de uma cultura em que a palavra volta a viver".

36 KSA 8, 30[1]

37 Cf. Burnett, Henry. A recriação do mundo: a dimensão redentora da música na filosofia de Nietzsche. Tese de doutorado apresentada à Unicamp, 2004, especialmente os capítulos "Música popular, poesia 
Nietzsche sumariamente importante: por um lado, como escreve Nietzsche, "vivenciamos o declínio da última arte - Bayreuth me convenceu disso" 38 e, por outro lado, a semântica do conceito de Erlebnis se altera se analisado intratextualmente e, neste caso, sobretudo após os textos do início da década de $80 .{ }^{39}$ Mesmo assim, o pano de fundo da tríplice semântica do conceito vai permanecer latente nos textos ainda após o rompimento com Wagner, o que não significa que Nietzsche desdobre o anseio romântico-panteísta até seus últimos escritos.

Além da relação entre o anseio por uma linguagem imediata capaz de exprimir a totalidade oculta dos sentimentos humanos, os textos de Nietzsche reverberam ainda tanto a hipótese da significabilidade como a dimensão estética da Erlebnis, inclusive após sua vivência com Wagner.

Em um apontamento póstumo de 1880 até a primavera de 1881, portanto já à época de Aurora, Nietzsche se refere precisamente à extrema significabilidade de uma Erlebnis ao contexto geral da vida. Não basta vivenciar, como um querer vivenciar; é preciso que cada vivência altere durante um longo período e de modo significativo a vida, tal como a vivência pessoal que Nietzsche experimentou com Wagner, cujos estreitos laços vão deixar marcas significativas em seus escritos posteriores: "a riqueza das relações cresce continuamente e tudo o que vemos e vivenciamos se torna profundamente significativo". ${ }^{40}$ A intensidade de cada Erlebnis se torna de tal modo importante que toda observação carrega consigo a significabilidade daquilo que se vivenciou, cujo substrato apesar de intensos, são inconscientes: "Os homens veem gradativamente um valor e um significado na natureza que, em si, ela não tem. O camponês vê seu campo com uma emoção de valor, o artista suas cores, o selvagem carrega seu medo e nós a nossa segurança; é um

e linguagem" e "Aquela música se não canta não é popular", para compreender em que medida faltou a Wagner precisamente a vivência da música popular, vivência esta que sobrou em Bizet. Cf. também o fragmento da primavera de 1871, KSA 7, 12[1], traduzido por Oswaldo Giacoia, In: Discurso 37 (2007), p. 167-181.

38 KSA 8, 30[139].

39 Estamos nos referindo à hipótese que, embora não abordada neste texto, refere-se à noção de Erlebnis como oposição à autobiografia, tal como a interpretação de Brusotti, M. Tentativo di autocritica. Genova: il melangolo, 1992. Nossa posição teórica, ao contrário de Brusotti, é que o conceito de Erlebnis deve ser compreendido como crítica "da razão da vida" (KSA 13, 24[8] p. 634), ou seja, uma espécie de autogenealogia e não autobiografia. Trata-se, pois, de compreender que Erlebnis expressa muito mais as condições sobre as quais o pensamento de Nietzsche se origina e se desenvolve, e não uma espécie de confissões de seu autor. Sobre o tema, cf. ainda Stegmaier, W. Nietzsches Kritik der Vernunft seines Lebens: Zur Deutung von „Der Antichrist“ und „Ecce Homo“. In: Nietzsche-Studien 21 (1992), p. 163-183.

40 KSA 9, 6[239] p. 261. 
constante e peculiar simbolizar e equiparar sem consciência. Nosso olho vê uma paisagem com toda nossa moralidade e cultura e costumes". ${ }^{41}$

A noção de significabilidade da vivência confere a ela o status de algo exclusivamente individual, de modo que cada vivência é estritamente pessoal e sentida diferentemente por cada um. Cada vivência constrói a roupagem própria de cada pessoa, absolutamente única e individual: "Cada ação continua a criar a nós mesmos, ela tece nossa colorida roupagem. Cada ação é livre, mas a roupagem é necessária. Nossa vivência - eis aí nossa roupagem" ${ }^{42}$ A radical individualidade das vivências, de modo que "elas são pra mim algo diferente do que são a você"43, atuam alterando significativamente o contexto da vida. "Em homens profundos todas as vivências duram muito tempo" ${ }^{4}$, ou seja, precisam queimar como madeira verde, num lento e gradual processo que se desdobra e modifica a própria vida, cujo significado remonta à intensidade que a Erlebnis representa "e não apenas ao conteúdo originalmente experimentado como tal. O que denominamos de enfático na Erlebnis significa, pois, algo tão inesquecível e insubstituível que ela é fundamentalmente inesgotável para a determinação compreensiva de seu significado". ${ }^{45}$

Originalmente, o conceito de Erlebnis tem ainda uma dimensão estética. Isso significa que o conteúdo da vivência não é determinado através de meios racionais, mesmo porque Erlebnis representa o rigoroso instante em que "sentimos" algo. Como explicamos em uma nota acima (cf. 17), desde a primeira ocorrência do termo Erlebnis em um dicionário, a palavra já traz uma diferença em relação à Erfahrung, que por sua vez, pressupõe a mediação lógica com as Erlebnisse, que são sua condição de possibilidade. Enquanto Erlebnis é imediatamente sentida, Erfahrung é a mediação lógica que tem na Erlebnis sua condição de possibilidade, porém, Erfahrung não tem o caráter da relação "imediata" com a vida, tal como tem a Erlebnis. Rigorosamente individuais, as Erlebnisse nos são sempre inconscientes e racionalmente

41 KSA 9, 6[239] p. 261. N'A Gaia Ciência 114, Nietzsche reitera a ideia de que, na medida em que somos capazes de vivências significativas, torna-se impossível qualquer observação neutra, seja moral, sensitiva, etc: "Ao vermos uma nova imagem, imediatamente a construímos com ajuda de todas as experiências que tivemos, conforme o grau de nossa retidão e equidade. Não existem vivências que não sejam morais, mesmo no âmbito da percepção sensível". Cf. ainda A 119 e KSA 12, 1[58].

42 KSA 10, 5[1]208 p. 211. Cf. a mesma noção da individualidade de cada vivência em um fragmento do verão de 1872 - início de 1873, KSA 7, 19[241]: "Nossas vivências determinam nosso indivíduo, e na verdade de tal modo que ele é determinado até a última célula segundo cada impressão de sentimento".

43 KSA 9, 6[239] p. 261.

$44 \mathrm{KSA} 10,5[1] 156$ p. 204. Cf. ainda KSA 10, 5[33].

45 Gadamer, Hans-G., op.cit., p. 73. Cf. ainda Visser, G., op.cit., p. 25: "Erlebnis mostra então que uma sensação só declara algo, atua sobre algo, se ela se insere na roupagem, no texto da vida". 
não-determináveis. ${ }^{46}$ Segundo Nietzsche, "um psicólogo nato se guarda, por instinto, de ver por ver; e o mesmo se pode dizer de um pintor", pois de outro modo Erlebnis perderia seu caráter de relação imediata com a vida: "O ter vivências quando é um querer-ter-vivências -, não resulta bem. Na vivência não é lícito olhar para si, toda visão se converte então em 'maldade do olho" ". ${ }_{4}{ }^{7}$ Em suma, Erlebnis é radicalmente estética-individual-imediata, cujo conteúdo permanece sempre pathetico e não racional.

A característica estética da Erlebnis ocorre desde a "Extemporânea" sobre Wagner. Como estética - ou pathos - "todas as vivências nos são conscientes só de sobressaltos". ${ }^{48}$ Contudo, não significa que elas não atuem, como vimos, de forma determinante no indivíduo: "A grande parte de nossas vivências é de incerteza e atua". ${ }^{49} \mathrm{O}$ que é enfatizado por Nietzsche nas vivências é que há "toda a vida orgânica" 50 e não um suposto "eu" por trás da vivência. Não se pode perder de vista que a "consciência é o último e derradeiro desenvolvimento do orgânico" 51 , cujo tema é caríssimo para toda filosofia de Nietzsche. Nas vivências não se trata apenas que "eu" as sinto (empfinde), mas, sobretudo, que eu as “sinto", e só depois é possível torná-las "conscientes" ou expressá-las através de signos de comunicação, vale dizer, em conceitos. ${ }^{52}$ Toda vivência é, pois, pathos que só se torna pessimamente consciente - logo, imensamente simplificada através da linguagem - depois de um tempo de digestão:

Quanto ao mais da vida, as chamadas "vivências", qual de nós pode levá-las a sério? Ou ter tempo para elas? Nas experiências presentes, receio, estamos sempre "ausentes": nelas não temos nosso coração - para elas não temos ouvidos. Antes, como alguém que divinamente disperso e imerso em si, a quem os sinos acabam de estrondear no ouvido as doze batidas do meio-dia, e súbito acorda e se pergunta "o

46 O importante em uma vivência é simplesmente que nela alguém "sente". Em vários textos tanto de juventude quanto nos últimos escritos, Nietzsche emprega indistintamente a palavra Erlebnis e Empfindung e, em alguns casos, inclusive como sinônimas, p.ex., em HH 211: "É sempre como foi com Aquiles e Homero: um tem a Erlebnis, a Empfindung, o outro as descreve". Ou ainda em ABM 268: "Palavras são sinais sonoros para conceitos; mas conceitos são sinais-imagens mais ou menos determinados, para Empfindungen recorrentes e associadas, para grupos de Empfindung". Cf. ainda a mesma hipótese em Sobre a verdade e mentira o sentido extra-moral, KSA 1, p. 879 e KSA 11, 34[86]. Cf. ainda Visser, G., op.cit., p. 23: "Para o jovem Nietzsche, Empfindung tem claramente um âmbito de contexto especial, com sensibilidade estética. [...] Também nos textos tardios Nietzsche emprega os conceitos de Empfindung e Erlebnis um ao lado do outro".

$47 \mathrm{Cl}$, Incursões de um extemporâneo 7. Cf. apontamento semelhante do outono de 1887, KSA 12, 9[110].

48 Co. Ext. IV, Richard Wagner in Bayreuth, 7. In KSA 1, p. 471.

49 KSA 11, 25[359] p. 107.

50 Cf. KSA 11, 26[94] p. 175.

51 GC 11.

52 Cf. Visser, G., op.cit., p. 24: "Erlebnis, ao contrário, afirma que todo sujeito da sensação, da percepção e da cada ação é sempre o organismo, a vida orgânica, e não um Eu consciente". 
que foi que soou?", também nós por vezes abrimos depois os ouvidos e perguntamos, surpresos e perplexos inteiramente, "o que foi que vivenciamos?", e também "quem somos realmente?", e em seguida contamos, depois, como disse, as doze vibrantes batidas da nossa vivência, da nossa vida, nosso ser - ah! E contamos errado... ${ }^{53}$

\section{O aforismo de Aurora intitulado Erleben und Erdichten ${ }^{54}$ parece} arrematar a incomensurabilidade da vivência. Nietzsche enfatiza novamente a característica da Erlebnis estreitamente ligada à vida orgânica e seus impulsos, que por sua vez, têm as "leis de sua alimentação" inteiramente desconhecidas de nós. Nietzsche se refere à ideia de que as Erlebnisse são desprovidas de quaisquer nexos racionais, de tal modo que a "alimentação" dos impulsos nas vivências são inteiramente obras do acaso, ou seja, completamente inconscientes e sem determinação racional de seu conteúdo; inclusive quase não será possível nomear esses impulsos:

Mal conseguirá dar o nome dos mais grosseiros a eles: o número e a intensidade deles, o fluxo e refluxo, o jogo recíproco e, sobretudo, as leis de sua alimentação, permanecem inteiramente desconhecidas para esse alguém. Esta alimentação será também obra do acaso: nossas vivências diárias lançam uma presa ora a esse, ora àquele impulso, que é avidamente apanhada, mas todo o ir-e-vir desses eventos está fora de qualquer nexo racional com as necessidades de nutrição da totalidade dos impulsos. [...] Nossas experiências, como disse, são todas, neste sentido, meios de alimentação, mas distribuídos com a mão cega [...].55

$\mathrm{O}$ aforismo de Aurora pertence à época em que o primado do intelecto em Humano, demasiado humano é substituído pela primazia do corpo, evento decisivo que ocorre já nos textos de Aurora. Apesar disso, a incomensurabilidade da Erlebnis, como vimos, não é prerrogativa apenas dos textos posteriores a $1880 .{ }^{56} \mathrm{Em}$ todo caso, Nietzsche enfatiza outra vez que os "pensamentos conscientes nos são os mais superficiais" 57 , pois vêm à luz somente pela vulgarização ou empobrecimento do todo da Erlebnis, sobretudo

53 GM, Prólogo 1. Tradução modificada. Cf. ainda HH II, Prefácio, 1 e ABM 285.

54 A 119.

55 A 119. O grifo é nosso.

56 Cf. Müller-Buck, Renate, "Ich schreibe nur, was von mir erlebt worden ist": Friedrich Nietzsches Briefe der achtziger Jahre. Dissertation zur Erlangung des akademischen Grades Doktor der Philosophie. Teil II. Technische Universität Berlin, 1998. p. 6s.: "Em Humano, demasiado Humano o instinto está subordinado ao intelecto, o pensamento inconsciente ao consciente. Isso muda com Aurora e é possível perguntar, se a mudança de pensamento de Nietzsche em Aurora não tem também algo a ver com a mudança na sua forma de vida. [...] O primado do intelecto é substituído precisamente nessa situação de ruptura através do primado do corpo. Já em Aurora se trata da dedução da razão e da moral a partir dos impulsos e sentimentos originais".

57 KSA 11, 26[94] p. 175. 
quando é comunicada através de signos de comunicação. Seu conteúdo, pois, nos é racionalmente obstruído.

A propósito da tentativa de tornar consciente ou compreender o conteúdo de uma vivência, o aforismo de Aurora relaciona Erleben e Erdichten. Obviamente, a compreensão do conteúdo de uma vivência só pode resultar em pura "linguagem figurada", ou seja, em Erdichten. A palavra no português não possui a correspondência semântica do alemão: Erdichten significa mais do que meramente "inventar", e a palavra pode ter tanto uma conotação positiva quanto negativa; ela está próxima do sentido de "poetar", mas não se confunde com ele, pois no caso de Erdichten se trata de uma invenção inteiramente fantasiosa que não deve ser levada a sério. ${ }^{58}$ Em relação ao aforismo, as tentativas de tornar conscientes ou racionalizar o conteúdo da Erlebnis resultam, necessariamente, em invenções fantasiosas "muito livres, muito arbitrárias" do substrato de impulsos que compõe a Erlebnis: "que também nossos juízos e valorações morais são apenas imagens e fantasias sobre um processo fisiológico de nós desconhecidos, uma espécie de linguagem adquirida para designar certos estímulos nervosos? Que tudo isso que chamamos de consciência é um comentário, mais ou menos fantástico, sobre um texto não sabido, talvez não 'sabível', porém sentido?". 59

A última parte do aforismo se refere a uma "vivência trivial", como diz Nietzsche: trata-se de uma situação em que "um dia, passando pelo mercado, notamos que alguém ri de nós". Na sequência, o texto traz à luz dois elementos aos quais já mencionamos: por um lado, alude à restrição da fundamentação racional de toda Erlebnis e, por outro lado, como a mesma "vivência trivial" é de tal modo radicalmente individual, a ponto de ser diferentemente vivenciada por cada pessoa - segundo a configuração de seu grupo de sensações -, e cujo significado deverá ser obliterado ou achatado quando for comunicado de forma compreensiva aos outros. Não por acaso nos referimos à Erlebnis como um conceito estético-individual que, para além de qualquer determinação racional, só tem sentido se pensada como pathos. Porém, dado que o anseio humano em fixar um conteúdo racional à Erlebnis é também inevitável, no sentido de torná-la compreensível ou consciente, Nietzsche conclui o aforismo perguntando se toda erdischtetes vivência não seria mera fabulação inventiva: "O que são, então, nossas vivências? São muito mais aquilo que nelas pomos

58 O termo é enfatizado na literatura alemã à época de Goethe. Neste aspecto, cf. o verbe „Erdichten“, In: Schadewaldt, Wolfgang. Goethe-Wörterbuch. Band 3. Hrsg. von der Berlin-Bradenburgischen Akademie der Wissenschaften. Stuttgart u.a.: Kohlhammer, 1998: "não deveria temer, | que você mais uma vez está mentindo pra nós e inventando de forma fantasiosa tais nomes?".

59 A 119. O grifo é nosso. 
do que o que nelas se acha! Ou deveríamos até dizer que nelas não se acha nada? Vivenciar não seria poetar fantasiosamente?". ${ }^{60}$

Nietzsche recepciona visivelmente o conceito de Erlebnis através da sua tríplice significação que, originalmente, determinou seu uso no vocabulário da literatura alemã. Seja a imediatez homem-mundo, a significabilidade para o contexto geral da vida e ainda a impossibilidade de comensurar racionalmente o conteúdo da vivência, ou seja, sua dimensão estética, todas elas encontram eco nos textos de Nietzsche. Erlebnis significa em Nietzsche também pathos. Ao longo dos seus escritos, o conceito recebe outras variações semânticas, como por exemplo, aquela indicada na nota 39 deste texto, vale dizer, Erlebnis como 'crítica da razão da vida' ou as condições sobre as quais uma teoria se origina e se desenvolve, quer dizer, Erlebnis como autogenealogia. ${ }^{61}$

\section{Referências bibliográficas}

BRUSOTTI, M. - Tentativo di autocritica. Genova: il melangolo, 1992. BURNETT, Henry. - A recriação do mundo: a dimensão redentora da música na filosofia de Nietzsche. Tese de doutorado apresentada à Unicamp, 2004.

CRAMER, K. - "Erleben, Erlebnis". In: RITTER, Joachim (Hrsg.) Historisches Wörterbuch der Philosophie. Band 2: D-F. Basel/Stuttgart: Schwabe \& Co. Verlag, 1972.

GADAMER, Hans-G. - Wahrheit und Methode: Grundzüge einer philosophischen Hermeneutik. Tübingen: J.C.B. Mohr, 1990.

GERHARDT, V. - Pathos und Distanz. Stuttgart: Reclam, 1988.

GIACOIA, O. - Música e Palavra. In: Discurso 37 (2007), p. 167-181.

MEYER-KALKUS, R. - Pathos. In: RITTER, Joachim (Hrsg.) Historisches Wörterbuch der Philosophie. Band 7: P-Q. Basel/Stuttgart: Schwabe \& Co. Verlag, 1989.

MÜLLER-BUCK, Renate - "Ich schreibe nur, was von mir erlebt worden ist": Friedrich Nietzsches Briefe der achtziger Jahre. Dissertation zur Erlangung des akademischen Grades Doktor der Philosophie. Teil II . Technische Universität Berlin, 1998.

NIETZSCHE, F. - Sämtliche Werke. Kritische Studienausgabe in 15 Bänden. (KSA) Hrsg. Giorgio Colli und Mazzino Montinari. Berlin/New York: DTV \& Walter de Gruyter, 1980.

60 A 119. Tradução modificada.

61 Sobre o assunto, cf. Viesenteiner, Jorge L. Erlebnis (vivência): autobiografia ou autogenealogia? Sobre a "crítica da 'razão da minha vida'” em Nietzsche. In: Estudos Nietzsche, Curitiba, v. 1, n. 2, p. 327-353, jul./ dez. 2010. 
- O Nascimento da Tragédia. (NT ) (Trad. J. Guinsburg). São Paulo: Companhia das Letras, 1992.

- Crepúsculo de los ídolos. (CI) (Trad. Andrés Sánchez Pascual). Madrid: Alianza Editorial, 1997.

- Além do bem e do mal. (ABM) (Trad. Paulo César de Souza). São Paulo: Companhia das Letras, 1998.

- Genealogia da moral. (GM) (Trad. Paulo César de Souza). São Paulo: Companhia das Letras, 1998.

- Humano, demasiado Humano (HH II ) (vol. 2): Miscelânea de Opiniões e Sentenças e $O$ Andarilho e sua Sombra (Tradução Rubens Rodrigues Torres Filho). In: Obras incompletas. Coleção Os Pensadores. São Paulo: Nova Cultural, 1999.

- Obras incompletas. Trad. Rubens Rodrigues Torres Filho. In: Coleção Os Pensadores. São Paulo: Nova Cultural, 1999.

- Humano, demasiado Humano. (HH) (Trad. Paulo César de Souza). São Paulo: Companhia das Letras, 2000.

- A Gaia Ciência. (GC) (Trad. Paulo César de Souza). São Paulo: Companhia das Letras, 2001.

- Aurora. (A) (Trad. Paulo César de Souza). São Paulo: Companhia das Letras, 2004.

- Ecce Homo. (EH) (Trad. Paulo César de Souza). São Paulo: Companhia das Letras, 2004.

SCHADEWALDT, Wolfgang - Goethe-Wörterbuch. Band 3. Hrsg. von der BerlinBradenburgischen Akademie der Wissenschaften. Stuttgart u.a.: Kohlhammer, 1998. STEGMAIER, W. - Nietzsches Kritik der Vernunft seines Lebens: Zur Deutung von „Der Antichrist“" und „Ecce Homo “. In: Nietzsche-Studien 21 (1992), p. 163-183.

- Nietzsches "Genealogie der Moral". Darmstadt: Wissenschaftliche Buchgesellschaft, 1994.

- „Philosophischer Idealismus“ und die „Musik des Lebens: zu Nietzsches Umgang mit Paradoxien. In: Nietzsche-Studien 33 (2004) p. 90-128.

- Philosophie der Orientierung. Berlin/New York: Walter de Gruyter, 2008.

TONGEREN, Paul v. (Hrsg) - Nietzsche Wörterbuch. Bd.1. Berlin: Walter de Gruyter, 2004.

VIESENTEINER, Jorge L. - Erlebnis (vivência): autobiografia ou autogenealogia? Sobre a "crítica da "razão da minha vida" em Nietzsche. In: Estudos Nietzsche, Curitiba, v. 1, n. 2, p. 327-353, jul./dez. 2010.

VISSER, Gerard - Erlebnisdruck: Philosophie und Kunst im Bereich eines Übergangs und Untergangs. Würzburg: Königshausen \& Neumann, 2005. 